\title{
Measurement of Natural Radioactivity Level in Selected Phosphate Fertilizer Samples Collected from Iraqi Markets
}

\author{
Yassamin S. Khalf* and Kareem K. Mohammad \\ Department of Physics, College of Science, Al-Nahrain University, Baghdad-Iraq
}

\begin{tabular}{|c|c|}
\hline Article's Information & Abstract \\
\hline $\begin{array}{l}\text { Received: } \\
\text { 16.07.2021 } \\
\text { Accepted: } \\
\text { 22.09.2021 } \\
\text { Published: } \\
\text { 30.09.2021 }\end{array}$ & \multirow{2}{*}{ 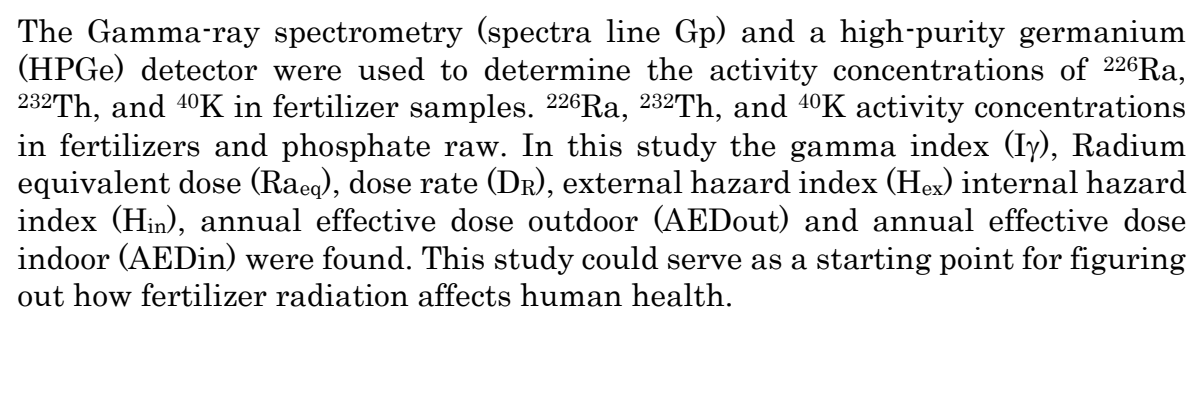 } \\
\hline $\begin{array}{l}\text { Keywords: } \\
\text { Natural radioactive } \\
\text { Spectroscopy } \\
\text { Fertilizer }\end{array}$ & \\
\hline
\end{tabular}

DOI: 10.22401/ANJS.24.3.07

*Corresponding author: yassaminphy@gmail.com

\section{Introduction}

The accumulation of primordial radionuclides like ${ }^{238} \mathrm{U}$ and ${ }^{232} \mathrm{Th}$, as well as their decay products and singly occurring ${ }^{40} \mathrm{~K}$, in soil and rocks of the environment, is directly influenced by terrestrial gamma radiation. Natural radioactivity and the resulting external gamma radiation exposure are primarily determined by local geological and geographical conditions, which vary in intensity in each location [1]. High-energy incident cosmic ray particles on the earth's atmosphere and radioactive nuclides that originate from the earth's crust and are present throughout the environment, including the human body, are the two main contributors to natural radiation exposures. Furthermore, industrial processes involving NORM may pose a radiological risk, so identifying and quantifying these risks is essential [2]. Fertilizers are important to ensure that crops obtain enough nutrients.to foster development and ensure a good harvest Fertilizers, on the other hand, may be harmful. Adulterated goods containing raw materials sourced from a variety of sources that are uncertain and/or suspect they can contain trace elements contaminants that are unintentionally added into soils, in addition to the certified nutritional ingredients for plants [3]. Phosphoric acid is the main raw material for phosphate fertilizers such as di ammonium phosphate (DAP), mono ammonium phosphate (MAP), potassium sulfate (K), Bitmous (B), urea ammonium phosphate (NP) single superphosphate (SSP), Nitrogen, Phosphorous and Potassium (NPK) which was made by reacting different amounts of $\mathrm{NH}_{3}$ phosphoric acid directly During the phosphate rock reaction with sulphuric acid, the radioactive equilibrium between ${ }^{238} \mathrm{U},{ }^{232} \mathrm{Th}$, and their decay products is broken, and the radionuclides migrate according to their solubility. Isotopes of uranium form highly soluble phosphate ion compounds, while ${ }^{210} \mathrm{~Pb}$ and ${ }^{210} \mathrm{Po}$ isotopes accumulate in phosphorgypsum [4]. Furthermore, fertilizer materials used in plant nitration processes, such as phosphates (which contain ${ }^{238} \mathrm{U}$ and ${ }^{232} \mathrm{Th}$ ) and ${ }^{40} \mathrm{~K}$, are considered important sources of soil contamination and radioactivity. Due to external exposure during a resident's time in the farms and internal exposure through ingestion, this phenomenon may result in potential radiological risks [5].

\section{Experimental Measurements}

\subsection{Sample collection and preparation}

The fertilizers were obtained from different sources and fertilizer types, including 17 samples of commonly used fertilizers (potassium sulfate, NPK, MAP Urea, NP, DAP, and Bitmous) and one sample of phosphate raw as indicate in Table 1. taken for gamma spectrometric analysis, the samples were placed in small, airtight containers and held for a month in (hood) to reach the nuclear equilibrium state between radium and its daughter products. After a month, we put the samples in a one-kilogram marinelli beaker that have been washed with plain water and then distilled water. The samples were then dried in an oven at $80{ }^{\circ} \mathrm{C}$ until they reached a constant weight [6]. 


\title{
Al-Nahrain Journal of Science
}

ANJS, Vol.24 (3), September, 2021, pp. 43-49

\begin{tabular}{l}
\hline \multicolumn{3}{|c|}{ Table1. Sample details. } \\
\begin{tabular}{||c|c|c||}
\hline Sample code & Sample ID & Origin \\
\hline \hline Y1 & Potassium sulfate & Iraq \\
\hline Y2 & Urea & Iraq \\
\hline Y3 & NPK & Jordan \\
\hline Y4 & MAP & Saudi \\
\hline Y5 & NP & Iraq \\
\hline Y6 & Potassium sulfate & Italia \\
\hline Y7 & DAP & Saudi \\
\hline Y8 & Bitmous & Romanian \\
\hline Y9 & MAP & Jordan \\
\hline Y10 & Urea & Iran \\
\hline Y11 & Potassium sulfate & Holland \\
\hline Y12 & NPK & United state \\
\hline Y13 & Bitmous & Turkey \\
\hline Y14 & Potassium sulfate & France \\
\hline Y15 & NPK & Holland \\
\hline Y16 & Urea & Iraq \\
\hline Y17 & NPK & Russia \\
\hline Y18 & Phosphate raw & Iraq \\
\hline \hline
\end{tabular}
\end{tabular}

\begin{abstract}
2.2 Measurement setup
The study used a high pure germanium detector supplied by (BSI Baltic scientific instruments) composed of a germanium crystal $(2 \times 2)(\mathrm{HPGe})$ and computer software (spectral line Gp) shown in Figure 1. To minimize the contribution of X-ray fluorescence, the detector was placed inside a thick $(4.5 \mathrm{~cm})$ lead shield to reduce back ground radiation. The inner surfaces of the lead shield were graded lining with Copper sheet to reduce the contribution of X-ray fluorescence $(0.8 \mathrm{~mm}$ thick). The main amplifier, amplifier, and power supply are all connected to the device. The calculated background for counting (2 hrs.) [14]. Standard sources (CBSS 2) ${ }^{241} \mathrm{Am}(59.3) \mathrm{Kev},{ }^{60} \mathrm{Co}(1173.1,1332.3)$ $\mathrm{Kev}$, and ${ }^{137} \mathrm{Cs}$ (661.6) Kev were used to calibrate the detector Table 2 . We counted each sample by placing it over the detector for ( $2 \mathrm{hrs}$.), we counted each sample by placing it over the detector for ( $2 \mathrm{hrs}$.), after which we measured the activity concentration of the samples by using software (spectral line Gp) as meantaited in Table 3. Some once spectrum of NP type of phosphate fertilizer (y5) shown in Figure 2.
\end{abstract}

Table 2. Calibration certificate radionuclides [12].

\begin{tabular}{||c|c|c|c|c||}
\hline Radionuclide & Half-life (days) & Activity (Bq/kg) & $\begin{array}{c}\text { Combined standard } \\
\text { uncertainty }\end{array}$ & Energy (Kev) \\
\hline \hline Am-241 & 157800 & 4.433 & 1.1 & 59.3 \\
\hline Cd-109 & 4626 & 16.17 & 1.5 & 88.1 \\
\hline Ce-139 & 137.5 & 0.740 & 1.1 & 165 \\
\hline Co-57 & 271.26 & 0.855 & 1.1 & $122.1,136$ \\
\hline Co-60 & 1925.4 & 2.659 & 1.1 & $1173.1,1332.3$ \\
\hline Cs-137 & 11019 & 2.439 & 2.2 & 661.6 \\
\hline Sn-113 & 115.1 & 3.087 & 1.5 & 592 \\
\hline Sr-85 & 64.78 & 4.024 & 1.2 & 898 \\
\hline Y-88 & 106.6 & 3.995 & 2.4 & $898.02,1836.08$ \\
\hline Hg-203 & 46.72 & 2.064 & & \\
\hline
\end{tabular}

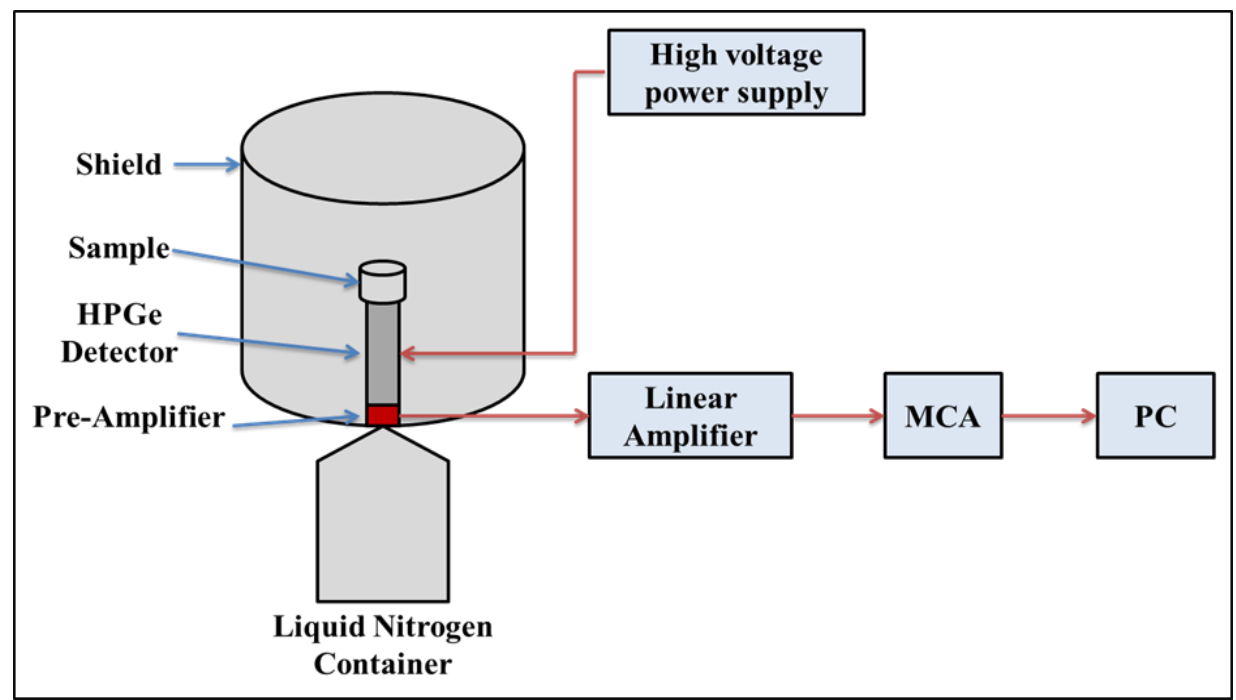

Figure 1. Experimental setup. 


\section{Al-Nahrain Journal of Science}

ANJS, Vol.24 (3), September, 2021, pp. 43-49

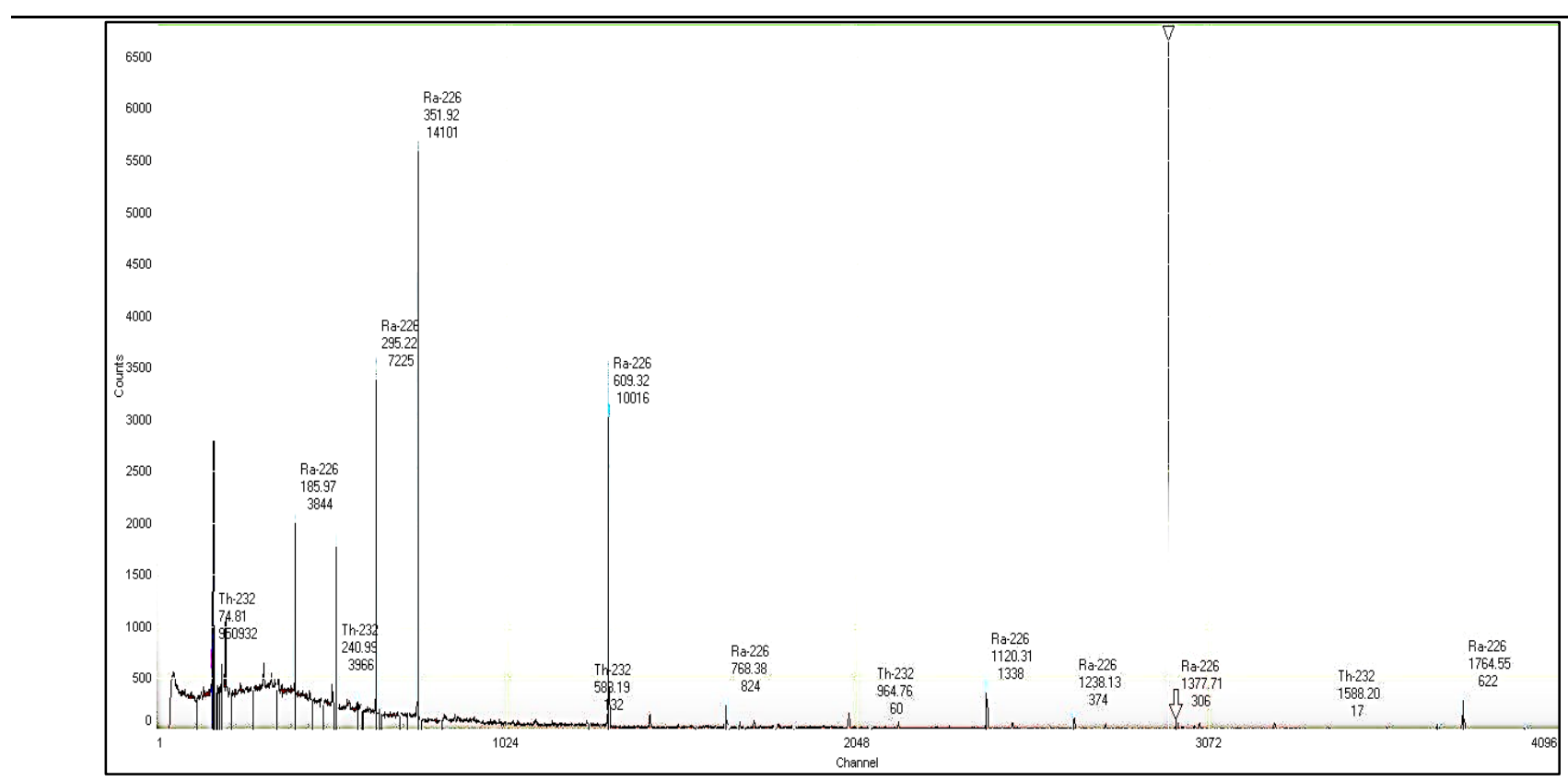

Figure 2. The spectrum of Np type phosphate fertilizer (y5).

\subsection{Theoretical calculations}

In this study, there are many parameters have been calculated, such as Activity concentration (A), Gamma index (I $\gamma$ ), Gamma dose absorption (DR), Radium equivalent activity (Raeq), Annaual effective dose (AED), Hazard indices external (Hex) and internal (Hin).

Activity concentration $(\boldsymbol{A})$ : The activity concentrations of natural radionuclides ${ }^{226} \mathrm{Ra},{ }^{232} \mathrm{Th}$ and ${ }^{40} \mathrm{~K}$ which is refer to number of nuclear decays per second can be calculated through $\gamma$-ray spectrometry by using the following formula [6]:

$$
A=N e t \text { count } /\left(\varepsilon \times I_{\gamma} \times T \times M\right)
$$

where $\varepsilon$ the absolute gamma peak efficiency of the detector, $\mathrm{I}_{\gamma}$ intensity for gamma-ray energy, $\mathrm{T}$ is the counting time for the measurement in seconds and $\mathrm{M}$ is the weight mass of the sample in $\mathrm{kg}$. The results of activity concentration of fertilizers show in Table 3.

Gamma index (I $\gamma)$ : The decay intensity of the specific energy peak (I $\gamma)$ was calculated using the following equation [8]:

$$
I_{\gamma}=\left(A_{R a} / 300\right)+\left(A_{T h} / 200\right)+\left(A_{K} / 3000\right)
$$

where $A_{R a}$ is the specific activity of ${ }^{226} \mathrm{Ra}, \mathrm{A}_{\mathrm{Th}}$ is the specific activity of ${ }^{232} \mathrm{Th}$ and $\mathrm{A}_{\mathrm{K}}$ is the specific activity of ${ }^{40} \mathrm{~K}$, the results of gamma index of fertilizers shows in Table 4.

Gamma dose absorption $\left(D_{R}\right):\left(D_{R}\right)$ amounts in the air $1 \mathrm{~m}$ above the ground surface were determined on the basis of guidance given by UNSCEAR for the uniform distribution of naturally occurring radionuclides [8]:

$$
\begin{aligned}
D_{R}(n G y / h)= & \left(A_{R a} \times 0.462\right)+\left(A_{T h} \times 0.604\right)+ \\
& \left(A_{K} \times 0.0417\right)
\end{aligned}
$$

The results of gamma dose absorption are shown in Table 4.

Radium equivalent activity ( $\left.\boldsymbol{R} \boldsymbol{a}_{e q}\right)$ : There is no uniform distribution of natural radioactive nuclides in the soil. The total exposure to radiation from ${ }^{226} \mathrm{Ra},{ }^{232} \mathrm{Th}$ and ${ }^{40} \mathrm{~K}$ nuclides was therefore expressed by radium equivalent activity $\left(\mathrm{Ra}_{\mathrm{eq}}\right)$ in $(\mathrm{Bq} / \mathrm{kg})$. The radium equivalent activity of soil samples was calculated using the following formula [8]:

$$
R a_{e q}=\left(A_{R a}\right)+\left(A_{T h} \times 1.43\right)+\left(A_{K} \times 0.077\right)
$$

The results of Radium equivalent activity show in Table 4. Annaual effective dose (AED): was estimated from the absorbed gamma dose concentrations $\left(D_{R}\right)$ by using the dose conversion factor $(F)$ of $0.7 \mathrm{~Sv} / \mathrm{Gy}$ with an AED outdoor occupancy factor of 0.2 and 0.8 for AED indoor and determined using the following formula [9]:

$$
A E D(\text { msv } / \text { year })=D_{R}(n G y / h) \times T \times F
$$

The results of annaual effective dose show in Table 4.

Hazard indices external $\left(H_{e x}\right)$ and internal $\left(H_{\text {in }}\right)$ : Described two indicators that describe internal and external radiation risks. The external hazard index is derived from the $\left(\mathrm{Ra}_{\mathrm{eq}}\right)$ expression on the assumption that its permissible maximum value (equal to unity) corresponds to $\mathrm{Ra}_{\mathrm{eq}}(370$ $\mathrm{Bq} / \mathrm{kg}$ ) upper limit. The external hazard index (Hex) is then defined as follows [12]:

$$
\begin{aligned}
& H_{e x}=A_{R a} / 370+A_{T h} / 259+A_{K} / 4810 \\
& H_{\text {in }}=A_{R a} / 185+A_{T h} / 259+A_{K} / 4810
\end{aligned}
$$

The results of hazal indices external $\left(\mathrm{H}_{\mathrm{ex}}\right)$ and internal $\left(\mathrm{H}_{\mathrm{in}}\right)$ show in Table 4. 


\section{Al-Nahrain Journal of Science}

ANJS, Vol.24 (3), September, 2021, pp. 43-49
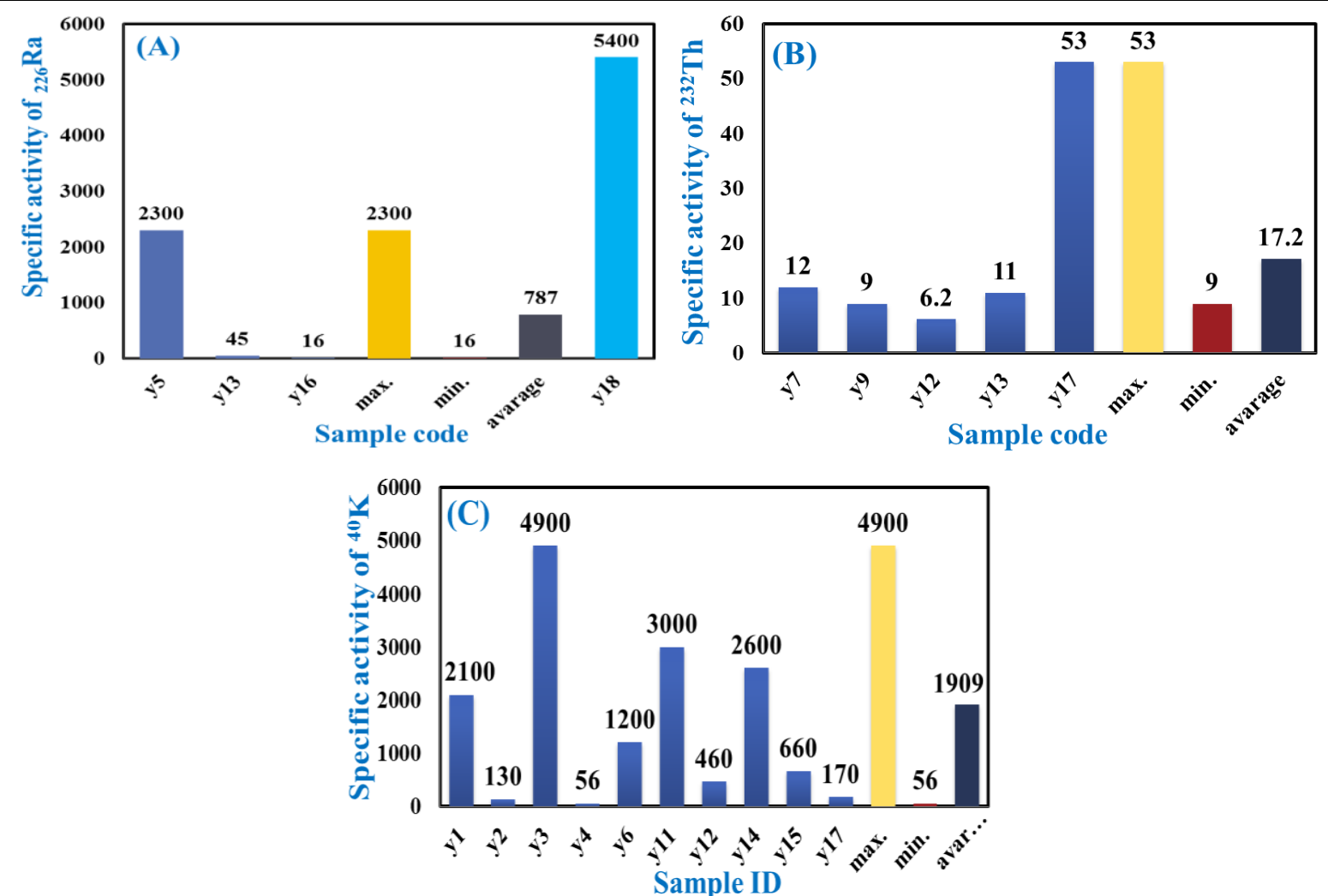

Figure 3. Specific activity for: (A) ${ }^{226} \mathrm{Ra}$, (B) ${ }^{232} \mathrm{Th},(\mathrm{C}){ }^{40} \mathrm{~K}$.

Table 3. The activity concentration of different types of fertilizers and phosphate raw.

\begin{tabular}{|c|c|c|c|}
\hline Sample code & Activity of ${ }^{226} \mathrm{Ra}(\mathrm{Bq} / \mathrm{kg})$ & Activity of ${ }^{232} \mathrm{Th}(\mathrm{Bq} / \mathrm{kg})$ & Activity of ${ }^{40} \mathrm{~K}(\mathrm{~Bq} / \mathrm{kg})$ \\
\hline $\mathrm{Y} 1$ & ND & ND & 2100 \\
\hline $\mathrm{Y} 2$ & ND & ND & 130 \\
\hline$\overline{\mathrm{Y} 3}$ & ND & ND & 4900 \\
\hline $\mathrm{Y} 4$ & ND & 9 & 56 \\
\hline $\mathrm{Y} 5$ & 2300 & ND & ND \\
\hline Y6 & ND & ND & 1200 \\
\hline Y7 & 12 & ND & ND \\
\hline$\overline{\mathrm{Y} 8}$ & $\mathrm{ND}$ & ND & $\mathrm{ND}$ \\
\hline Y9 & ND & 12 & ND \\
\hline Y11 & $\mathrm{ND}$ & ND & 3000 \\
\hline Y12 & ND & 6.2 & 460 \\
\hline Y13 & $\mathrm{ND}$ & 11 & ND \\
\hline Y14 & ND & ND & 2600 \\
\hline Y15 & ND & ND & 660 \\
\hline Y17 & ND & 53 & 170 \\
\hline Y18 & 5400 & ND & ND \\
\hline
\end{tabular}

*ND: detection limit 


\title{
Al-Nahrain Journal of Science
}

\author{
ANJS, Vol.24 (3), September, 2021, pp. 43-49
}

Table 4. For different type of fertilizers The radiological hazards including gamma ray index (I $\gamma$ ), absorbed dose rate (D) and radium equivalent activity (Raeq), internal (Hin) and external (Hex) hazard indices, internal (AEDEin) and external (AEDEex) annual effective dose.

\begin{tabular}{|c|c|c|c|c|c|c|c|}
\hline Sample Code & $\mathbf{I} \gamma$ & DR(nGy/h) & Raeq Bq/kg & $\mathbf{H}_{\text {in }}$ & $\mathbf{H}_{\text {ex }}$ & 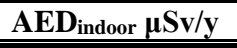 & AEDoutdoor $\mu \mathrm{Sv} / \mathrm{y}$ \\
\hline Y1 & 0.7 & 87.57 & 161.7 & 0.43 & 0.43 & 0.42 & 0.10 \\
\hline $\mathrm{Y} 2$ & 0.043 & 54.21 & 10.01 & 0.027 & 0.027 & 0.26 & 0.066 \\
\hline Y3 & 1.63 & 204.33 & 343 & 1.018 & 1.018 & 1.002 & 0.250 \\
\hline Y4 & 0.063 & 7.76 & 17.18 & 0.041 & 0.041 & 0.03 & 0.0095 \\
\hline $\mathrm{Y} 5$ & 7.66 & 1062.6 & 2300 & 12.4 & 12.4 & 5.21 & 1.3 \\
\hline Y6 & 0.4 & 50.04 & 92.4 & 0.42 & 0.24 & 0.24 & 0.06 \\
\hline $\mathrm{Y7}$ & 0.06 & 7.24 & 17.16 & 0.04 & 0.04 & 0.03 & 0.0088 \\
\hline Y9 & 0.06 & 7.24 & 17.16 & 0.046 & 0.046 & 0.03 & 0.0088 \\
\hline Y11 & 1 & 125.1 & 231 & 0.623 & 0.62 & 0.61 & 0.15 \\
\hline Y12 & 0.18 & 22.92 & 44.28 & 0.119 & 0.119 & 0.11 & 0.028 \\
\hline Y13 & 0.055 & 6.64 & 15.73 & 0.04 & 0.04 & 0.03 & 0.0081 \\
\hline Y14 & 0.86 & 108.42 & 200.2 & 0.54 & 0.54 & 0.53 & 0.132 \\
\hline Y15 & 0.22 & 25.02 & 46.2 & 0.13 & 0.12 & 0.13 & 0.03 \\
\hline $\mathrm{Y} 17$ & 0.32 & 39.1 & 88.8 & 0.23 & 0.23 & 0.19 & 0.04 \\
\hline Y18 & 18 & 2494.8 & 5400 & 29.18 & 29.18 & 12.23 & 3.05 \\
\hline Min & 0.043 & 6.64 & 10.01 & 0.027 & 0.027 & 0.03 & 0.0081 \\
\hline Max & 18 & 2494.8 & 5400 & 29.18 & 14.56 & 12.23 & 3.05 \\
\hline
\end{tabular}

\section{Results and Discussion}

The spectra of 17 fertilizer samples different types from different markets in Iraq, as well as one phosphate raw sample from phosphate quarries in Al-Qaim, Iraq, were analyzed. Table 2 . presents the activity concentrations of natural radioactive nuclides ${ }^{226} \mathrm{Ra},{ }^{232} \mathrm{Th}$, and ${ }^{40} \mathrm{~K}$. Phosphate row and $\mathrm{Np}$ type Iraqi phosphate fertilizer had the highest and lowest concentrations of ${ }^{226} \mathrm{Ra}$, with $5400 \mathrm{~Bq} / \mathrm{kg}$ and $2300 \mathrm{~Bq} / \mathrm{kg}$ respectively as shown in Figure 3(A). With 53 $\mathrm{Bq} / \mathrm{kg}$, NPK Russian phosphate fertilizer had the highest concentration of ${ }^{232} \mathrm{Th}$. The lowest concentration of ${ }^{232} \mathrm{Th}$ was found in NPK American fertilizer, which had a concentration of $6.2 \mathrm{~Bq} / \mathrm{kg}$ as shown in Figure 3(B). NPK Jordanian fertilizer had the highest activity concentration of ${ }^{40} \mathrm{~K}$ at $4900 \mathrm{~Bq} / \mathrm{kg}$, while MAP Saudi fertilizer had the lowest activity concentration at $56 \mathrm{~Bq} / \mathrm{kg}$ as shown in Figure 3(C). The other two Urea samples showed no activity because their ores lost naturally occurring radionuclides. In this study, activity concentrations in fertilizer samples from various countries were found to be within acceptable limits, which are $2300 \mathrm{~Bq} / \mathrm{kg}$ for ${ }^{238} \mathrm{U}, 460 \mathrm{~Bq} / \mathrm{kg} \mathrm{Bq} / \mathrm{kq}$ for ${ }^{232} \mathrm{Th}$, and $10000 \mathrm{~Bq} / \mathrm{kq}$ for ${ }^{40} \mathrm{~K}$, respectively (IAEA). We noticed that the activity concentrations of ${ }^{226} \mathrm{Ra}$ in raw phosphate were higher than the global average, while the activity concentrations of ${ }^{232} \mathrm{Th}$ were within the global average. All samples had activity concentrations of ${ }^{40} \mathrm{~K}$ that were lower than the global average (IAEA). Table 4. shows the results of hazard indices, the highest value of gamma index I $\gamma$ was 18 in phosphate raw, while its lowest value of was 0.043 in Urea Iraqi fertilizer as shown in Figure 4(A) The study indicates that the gamma index values for the investigated were more than the recommended value of 1 for the gamma index provided by (UNSCEAR, 2000) [1]. The maximum value of absorbed gamma dose rate $\left(D_{R}\right)$ was found to be $2494 \mathrm{nGy} / \mathrm{h}$ in phosphate raw, while the minimum value was found to be $6.64 \mathrm{nGy} / \mathrm{h}$ in Bitmous Turkish as shown in Figure 4(B). The present findings revealed that absorbed gamma dose rate values were higher than the recommended value of $55 \mathrm{nGy} / \mathrm{h}$ for the absorbed gamma dose rate provided by (UNSCEAR, 2000) [1]. The overall $\mathrm{Ra}_{\mathrm{eq}}$ is $5400 \mathrm{~Bq} / \mathrm{kg}$ in phosphate raw, which is a high value as compared to the ICRP recommended value. The minimum value is $10.01 \mathrm{~Bq} / \mathrm{kg}$ in Urea Iraqi fertilizer as shown in Figure $4(\mathrm{C})$, which is acceptable. The external hazard $\mathrm{H}_{\mathrm{ex}}$ values ranging from 14.59 to 0.027 in Urea and phosphate raw respectively indicate that certain fertilizers have an external threat greater than unity and more than the action level as shown in Figure 4(E). The internal hazard $\mathrm{H}_{\text {in }}$ values ranging from 29.18 to 0.02 in Urea and phosphate raw respectively as shown in Figure 4(D) indicate that certain fertilizers have an external threat greater than unity and more than the action level. The highest value of outdoor annual effective dose equivalent $\mathrm{AED}_{\text {out }}$ was $3.05 \mathrm{mSv} / \mathrm{y}$ in phosphate raw, while its lowest value of outdoor annual effective dose equivalent was $0.0081 \mathrm{mSv} / \mathrm{y}$ in Bitmous Turkish as shown in Figure 4(G), in the study indicate that the outdoor annual effective dose equivalent values for the investigated were more than the recommended value of $1 \mathrm{mSv} / \mathrm{y}$ for the outdoor annual effective dose equivalent provided by (UNSCEAR, 2000) [1]. The highest value of outdoor annual effective dose equivalent $\mathrm{AED}_{\text {in }}$ was $12.23 \mathrm{mSv} / \mathrm{y}$ in phosphate raw, while its lowest value of outdoor annual effective dose equivalent was $0.03 \mathrm{mSv} / \mathrm{y}$ in (Saudi DAP, Jordanian MAP and Turkish Bitmous) as shown in Figure 4(F), in the study indicate that the indoor annual effective dose equivalent values for the investigated were more than the recommended value of $1 \mathrm{mSv} / \mathrm{y}$ for the indoor annual effective dose equivalent provided by (UNSCEAR,2000) [1]. The results demonstrate that the fertilizers have a wide spectrum of gamma activity. 


\section{Al-Nahrain Journal of Science}

ANJS, Vol.24 (3), September, 2021, pp. 43-49

This could be as a result of the following factors:

1. The many sites where raw minerals for fertilizer production were sourced.

2. The distinctions between fertilizer factories that generate fertilizer.

3. The characteristics of radioactive elements in raw materials varied depending on where they were discovered.
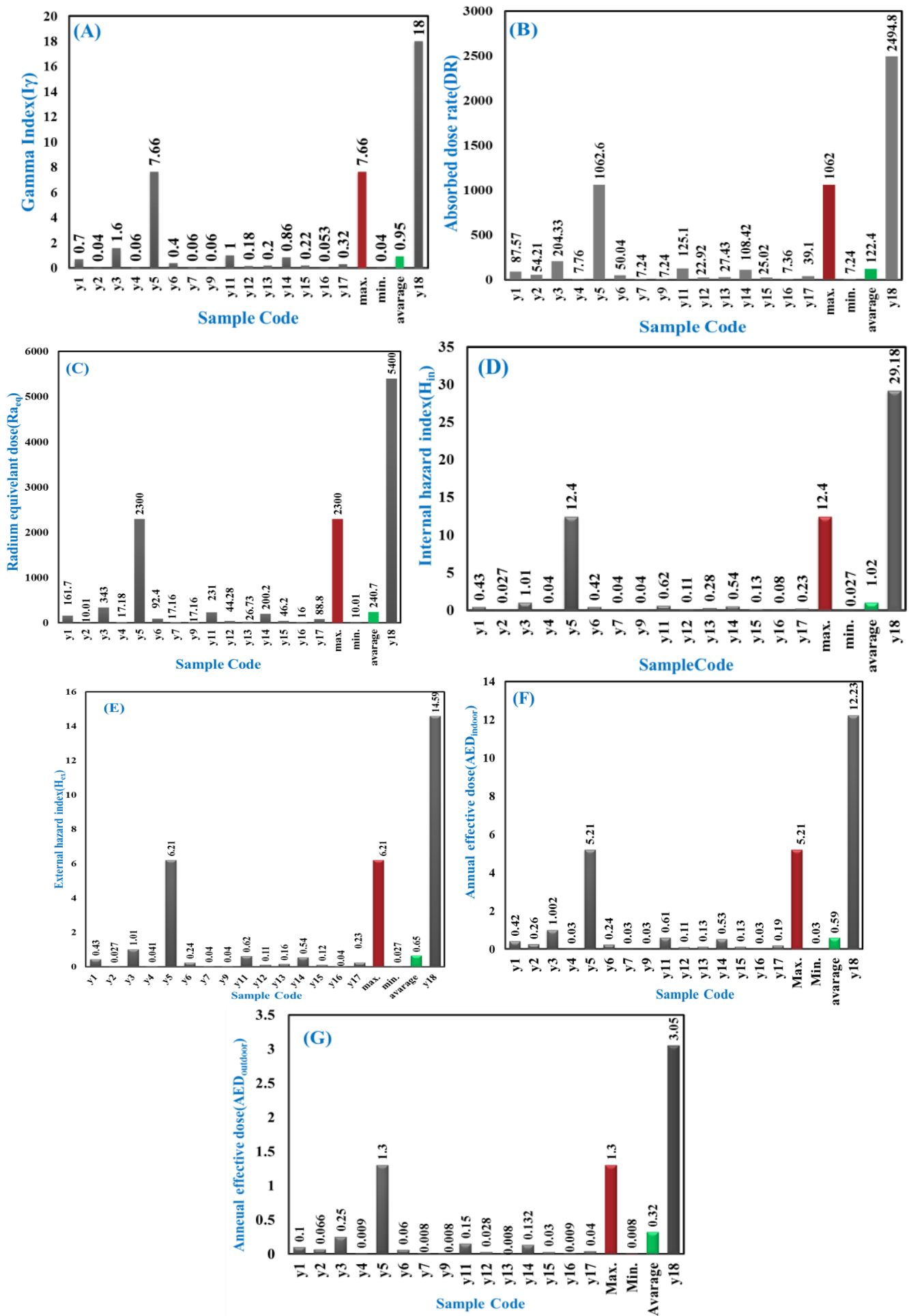

Figure 4. The Hazard indices of phosphate fertilizers. 


\section{Al-Nahrain Journal of Science}

ANJS, Vol.24 (3), September, 2021, pp. 43-49

4. Conclusions

1. The activity of fertilizer samples within the global word limit

2. Plant and animal fertilizers are preferred over artificial fertilizers because low level of radioactivity in plant and animal fertilizers.

3. High activity concentration in phosphate raw because it was random sample.

\section{Aim of Study}

The aim of this study is to measure the concentration of natural radioactivity in fertilizer samples and calculate the hazard indices of these radionuclides.

\section{References}

[1] Unscear; "Effects of Atomic Radiation to the General Assembly, in United Nations Scientific Committee on the Effect of Atomic Radiation". United Nations: New York, 2000.

[2] Eyakifama H. and Cebastien J. G. S.; "Preliminary assessment of natural radioactivity and associated radiation hazards in a phosphate mining site in southern area of Togo". Radiation Detection Technology and Methods, 2019.

[3] Wentao J. A. and Weiping C.; "Environmental risks of trace elements associated with long-term phosphate fertilizers applications: A review". Environmental Pollution, 168, 44-53, 2012.

[4] Mehrdad C.; Bahareh L.; Hajar M.; Nasim R.; "Heavy metal risk assessment for potatoes grown in overused phosphate-fertilized soils". Environ Monit Assess, 185, 2013.

[5] Dhuha R. M.; "Measurements of radioactivity levels in water and sediments near two power plants in Baghdad city". Thesis, 2018.

[6] Jabbar H. J. and Abdul R. H. S.; "Natural radioactivity of some local and imported fertilizers in Basrah Governorate/Iraq". Archives of Physics Research, 5, 1822, 2014.

[7] Al-Mousawi N. G. and Raghad S. M.; "Radiation hazards assessment of phosphate fertilizers used in Latifiyah region, Iraq". Applied Science, 73-80, 2020.

[8] Unscear, "Effects of Atomic Radiation to the General Assembly, in United Nations Scientific Committee on the Effect of Atomic Radiation". United Nations: New York, 1994.

[9] Hiwa H. A. and Habeeb H. M.; "Effect of Using Chemical Fertilizers on Natural Radioactivity Levels in Agricultural Soil in the Iraqi Kurdistan Region". J. Environ. Stud.; 29(2), 2020.

[10] International atomic energy agency (IAEA); "Extent of Environmental Contamination by Naturally Occurring Radioactive Material (NORM) and Technological Options for Mitigation". Technical Reports Series, (4I9), 2003.

[11] Raad O. H. and Hayder H. H.; "Investigation the natural radioactivity in local and imported chemical fertilizers" Brazilian archives of biology and technology, 54(4), 2011.

[12] Ashraf A. M. T.; "Measuring of natural radioactivity for ground waters in Tallafar district using gamma ray spectroscopy". Thesis, 2020.

[13] Hameed P. S.; Pillai G. S. and Mathiyarasu R.; "A study on the impact of phosphate fertilizers on the radioactivity profile of cultivated soils in Srirangam (Tamil Nadu, India)". Journal of Radiation Research and Applied Sciences, 1-9, 2014.

[14] Basim K. R.; "Measurement of Natural and Artificial Radioactive Elements in Soil at the Southern Al-Dora Region, Baghdad Governorate, Iraq". Journal of Nature, Life and Applied Sciences, 4, 83-93, 2020. 